\title{
The Impact of Food Rumors handling procedures on restaurants' image and customers' purchasing decision: A research in Fayoum
}

Samar N. khalaf

Mohammed A. Morsy

Mohammed S. Hassan

Faculty of Tourism and Hotels- Fayoum University

\begin{abstract}
:
The solutions and procedures used by the local restaurant managers in dealing with food rumors have a great impact on the mental image of the restaurant and customers purchasing decision. Various studies have shown that the strategies used by local restaurant managers to handle the crisis of food rumors, which lead to restore customer confidence and improve the mental image of the restauranta. The purpose of this paper is to identify the impact of food rumors handling procedures on restaurants' image and customers' purchasing decision of local restaurant. To achieve the objectives of the research 400 questionnaires were distributed on restaurant customers. The response rate was $80 \%$. The findings show that there is a significant impact of the solutions and procedures used by local restaurants to handle food rumors on the mental image and there is a significant impact of the solutions and procedures used by local restaurants to handle food rumors on the customer purchasing decision. The study recommended restaurant managers should do more work on differentiating their image, specifically through symbols and branding and restaurants should consistently provide quality products and services, such as serving food in promised time, serving ordered food accurately, and staff should be knowledgeable about menus, convenient operating hours, and ensure appearance.
\end{abstract}

Keywords: Food Rumors, Mental Image, Purchasing Decision, Local Restaurant.

\section{Introduction}

The impact of a restaurant's image is particularly significant in the restaurant industry because the intangible characteristics of a restaurant cannot be evaluated prior to the dining experience. As a result, customers are highly dependent on the image of the restaurant created by tangible cues (e.g. brand name of the restaurant or restaurant attributes) (Jeong, 2010).

In a food rumor situation, Kimmel (2004) found that the serious consequences of a negative rumor can be determined by how consumers perceive and feel about the restaurant image. In particular, it that are easily identifiable by customers (i.e., have high public awareness) may be more vulnerable to a rumor, because attribution of the rumors tends to be lesser known brands than with those that are better-known.

Some studies (Coombs, 2007) assert denial and attack the accuser strategies are the best strategies to use in a food rumor situation and other studies emphasize that denial is not enough to recover their tarnished brand reputation (Cheah et al, 2007).

\section{Definitions of mental image and customer decisions:}

Restaurant image is a symbolic construct created within the minds of people and consists of all the information and expectations associated with a product or service (Schulz, 2012).

Khatib (2016) defines customer decisions Process as stages which customer pass through to (1) identify their needs, (2) collect information, (3) evaluate alternatives, and (4) make the purchase decision as determined by psychological and economic factors, and are influenced by environmental factors such as cultural, group, and social values.

\section{Strategies and procedures to deal with food rumors:}

There is a set of procedures and solutions used by local restaurant managers to deal with food rumors as follows; rumor denial strategy aim to remove any possible links between a restaurant 
and the crisis (Frandsen,2011), diminish strategy is to persuade the general public about the lack of controllability of the crisis by the restaurant (Kaur,2013), rebuild strategies are a key type of strategy in crises to offset negativity and recover a restaurant's tainted reputation (Dwivedi,2007) and bolstering strategy refers to a secondary communication strategy (Coombs, 2012), In contrast to primary strategies, the bolstering strategy offers an opportunity to develop a restaurant's reputation by ensuring the safety of its products after a crisis (Dalal et al,2015).

\section{The Impact of Food Rumors handling procedures on restaurants' image and customers' purchasing decision:}

1. Crises offers organizational change opportunities.

Crises offer change and reconstruction opportunities to organizations, besides threats (Keeffe, 2008). Nowadays most of the managers and scholars argue that, crises can be regarded as: questioning the assumptions which cannot arguable other times, to get opportunity to test targets, experiences, habits, choices, worries, to start strategical and technological changes, discovering new talents and building a team spirit in the organization. First condition for benefiting from crises is to understand the fact that crises also accommodates opportunities (Ogba and Zhenzhen, 2009).

2. Crises offer organizations learning opportunities.

To prevent similar crises, which can happen near future, organizations should learn the lessons from past crises. By learning from experience, you can make sure the same mistakes are not made (McCreadie, 2015). In theory, learning requires feedback. With feedback, organizations can learn to increase the accuracy of their response and improve their performance. In all learning theories, feedback that enables performance improvements is of a form that allows a determination of "how close are we to the goal?". The more accurate feedback, the more rapid feedback, the better organizational performance (Jaques, 2008 ).

3. Crises offers organizations opportunities for growth.

Crises are time for growth for organizations which can benefit from it. It should not be forgotten that, crises offers great opportunities to organizations to strengthen trusts on costumers eyes and make the staff proud of their organization (Kimmel, 2010).

4. Increase satisfaction and loyalty of costumers.

Customer satisfaction is a person's feelings of pleasure or disappointment that result from comparing a product's perceived performance to their expectations (Kotler and Keller, 2006). Thus, a customer is considered dissatisfied if the outcome of the interaction falls short of expectations, satisfied if it matches expectations and delighted if it exceeds expectations. Customer satisfaction is therefore an overall evaluation based on the purchase and consumption experience with a product or service over time (Tarus and Rabach, 2013).

5. Improve the mental image of the restaurant's customers.

Restaurant image is believed to moderate the relationship between customer service value, service quality, customer satisfaction and customer loyalty (Ryu and Kim, 2009). First, customers have an expectation gap that normally guides the purchase decision. In most cases, customers' expectations depend on the image of the Restaurant such that restaurants with good image may influence the way the customers perceive their products and the value perception. Because perceived customer value is more of mental image of the value derived from the firms' service, restaurants with good image and reputation is likely to cloud the mind of the customer with high value expectation, thus, it is clear to us that the food crises and the correct methods and the right solutions to deal with it, improve the mental image of the restaurant's customers (Saaksjarvi, 2017). 


\section{Methodology:}

Research Hypotheses

H1. There is impact of the solutions and procedures used by local restaurants to handle food rumors on mental image.

$\mathrm{H} 2$. There is impact of the solutions and procedures used by local restaurants to handle food rumors on the customer purchasing decision.

Figure (1): Research framework

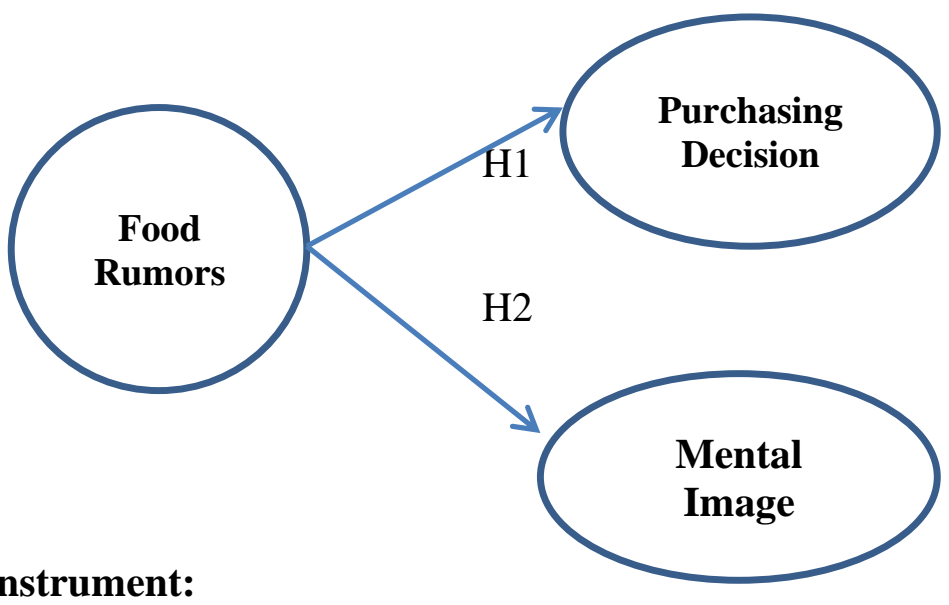

\section{Data Collection Instrument:}

Questionnaire was the main instruments used in gathering data. Open and close ended questions were used. Data was gathered from both primary and secondary sources. Secondary sources of data were from books, the internet, journals, magazines and newspapers.

The questionnaire form of customers is divided into two parts. Each part includes some sections. The first part consists of one section with four questions that intend to reveal the demographic data of customers such as gender, age, education and to specify his best restaurant.

The second part consists of four questions designed on a form of 5 Rating Scale (1=Strongly Disagree, 2= Disagree, 3=Neutral, 4= Agree and 5=Strongly Agree).

The first section of the questionnaire form consists of three parts that intend to identify means of spreading rumors. The first part aims to identify the role of social media in spreading rumors and supported by the following references (Kaplan and Haenlein 2010-kaur, 2013- Wilden et al, 2010- Kaynar, 2016).

The second part is trying to understand the reasons of spreading rumors on mass media (PressT.V-Radio) and supported by the following references such as (Kimmel, 2004Saffery, 2004Zheltukhina et al, 2016- Kang, 2013).

The following references and the third part aim to identify the role of rumor mongers in spreading rumors. The second section of the questionnaire is to show the impact of food rumors on the purchasing decision and supported by the following references such as (East et al, 2008Evans, et al, 2009- Khatib ,2016- East et al, 2008- Dev et al., 2015).

The third section of the questionnaire intends to highlight the impact of food rumors on the mental image of a restaurant (Ryu et al., 2008 - Aditya, 2014-Jeong, 2010- Choi, 2017).

The fourth section of the questionnaire intends to identify customers' opinions on proceedings taken by restaurant to face food rumors and supported by the following references such as (Dwivedi, 2007-Frandsen, 2011 Coombs, 2012-Dalal et L,2015). 


\section{Population and Sampling:}

The study population includes all local restaurant customers in Fayoum city.

Local restaurant customers are an unlimited population, so the researcher uses the formula of Thompson (2012) for random sample to calculate the number of restaurant mangers as below:

$$
n=\frac{N \times p(1-p)}{\left[N-1 \times\left(d^{2} \div z^{2}\right)\right]+p(1-p)}
$$

- Where, $\mathrm{n}$ : size of sample $\quad \mathrm{N}$ : population of sample

- $\quad \mathrm{z}=$ level of confidence according to the standard normal distribution (for a level of confidence of $95 \%, \mathrm{z}=1.96$.

- $\mathrm{p}=$ Estimated proportion of the population that presents the characteristic (when unknown we use $\mathrm{p}=0.5$ )

- $\mathrm{d}=$ Tolerated margin of error

- Therefore, with $\mathrm{d}=5 \%$ (at $95 \%$ confidence level), the sample size for the study is computed as below:

$$
\mathrm{n}=\frac{3676323 \times 0.5(1-0.5)}{\left[16285707-1 \times\left((0.05)^{2} \div(1.96)^{2}\right)\right]+0.5(1-0.5)}=384
$$

The total number of questionnaire was 500 copies, distributed on restaurant customers by a random sample, 400 were returned. The response rate reached $80 \%$.

\section{Customers profile:}

The following table showed that information about respondents such as, gender, age, educational level and specify best restaurant.

\begin{tabular}{|c|c|c|c|}
\hline & & Frequency & Percentage $\%$ \\
\hline \multirow[t]{2}{*}{ Gender } & Male & 219 & 54.8 \\
\hline & Female & 181 & 45.3 \\
\hline \multirow[t]{4}{*}{ Age } & $15-25$ years & 123 & 30.8 \\
\hline & $<25-35$ years & 183 & 45.8 \\
\hline & $<35-45$ years & 73 & 18.3 \\
\hline & More than 45 years & 21 & 5.3 \\
\hline \multirow{4}{*}{$\begin{array}{c}\text { Educational } \\
\text { level }\end{array}$} & High school & 66 & 16.5 \\
\hline & University & 252 & 63.0 \\
\hline & Master Degree & 45 & 11.3 \\
\hline & Doctorate Degree & 37 & 9.3 \\
\hline \multirow{11}{*}{$\begin{array}{l}\text { specify best } \\
\text { restaurant }\end{array}$} & Afandena & 26 & 6.5 \\
\hline & Bahya & 41 & 10.3 \\
\hline & El khedewy & 15 & 3.8 \\
\hline & El Rayes & 10 & 2.5 \\
\hline & El shamy & 9 & 2.3 \\
\hline & El zawy & 8 & 2.0 \\
\hline & Katkot & 2 & .5 \\
\hline & king fish & 11 & 2.8 \\
\hline & Lazania & 2 & .5 \\
\hline & Ozy & 98 & 24.5 \\
\hline & Pizaa roma & 12 & 3.0 \\
\hline
\end{tabular}

Table (2): Descriptive statistics of the profile 
International Journal of Heritage, Tourism and Hospitality Vol. (13), No. (2), September, 2019 By: Faculty of Tourism and Hotels, Fayoum University

\begin{tabular}{|c|c|c|c|}
\hline \multirow{4}{*}{} & Primo & 122 & 30.6 \\
\cline { 2 - 4 } & Rizo & 4 & 1.0 \\
\cline { 2 - 4 } & Rosto & 7 & 1.8 \\
\hline
\end{tabular}

The descriptive statistics showed that, $54.8 \%$ of the respondents are males while $45.3 \%$ of them are females. $30.8 \%$ of the respondents are between 15 and 25 years, $45.8 \%$ of them are between 25-35 years, $18.3 \%$ are between 35-45 years and 5.3\% more than 45 years. $16.5 \%$ of the respondents are holding high school education, $63.0 \%$ of them are holding university education, $11.3 \%$ are MSc holders and $9.3 \%$ are $\mathrm{PhD}$ holders. $6.5 \%$ of the customers prefer Afandena retaurant, $10.3 \%$ of them like Bahya restaurant, 3.8\% of them want to eat in El khedewy restaurant, $2.5 \%$ of respondents like eat in El Rayes restaurant, 2.3\% of them prefer El shamy restaurant, $2.0 \%$ want to lunch in El zawy restaurant, .5\% of respondents prefer to go to Katkot restaurant, $2.8 \%$ of them eating in king fish restaurant, $.5 \%$ of customers prefer Lazania restaurant, $24.5 \%$ of them eating in Ozy restaurant $3.0 \%$ of respondents prefer Pizaa roma restaurant, $30.6 \%$ of them want to eat in Primo restaurant, $1.0 \%$ of them love to eat in Rizo restaurant, $1.8 \%$ of respondents like eat in Rosto restaurant and $8.3 \%$ of them prefer Wings restaurant.

\section{Descriptive statistics analysis for customers}

- The impact of food rumors on the purchasing decision

Table (3): Descriptive statistics of the impact of food rumors on the Purchasing decision

\begin{tabular}{|c|c|c|c|c|c|c|c|c|}
\hline \multirow{2}{*}{$\begin{array}{l}\text { The impact of food rumors on the } \\
\text { purchasing decision }\end{array}$} & \multirow[t]{2}{*}{$\mathrm{N}$} & \multirow[t]{2}{*}{ Mean } & \multirow[t]{2}{*}{$\mathrm{SD}$} & \multicolumn{5}{|c|}{ Percentage } \\
\hline & & & & 1 & 2 & 3 & 4 & 5 \\
\hline $\begin{array}{l}\text { 1- Food rumors affect me } \\
\text { generally about not having } \\
\text { food outside. }\end{array}$ & 400 & 3.96 & 1.39 & 14.8 & 16.5 & 9.3 & 34.4 & 25 \\
\hline $\begin{array}{l}\text { 2- Food rumors cause me not to } \\
\text { have food at restaurants for a } \\
\text { short time. }\end{array}$ & 400 & 4.12 & 1.41 & 15 & 15.3 & 10.3 & 31.8 & 27.6 \\
\hline $\begin{array}{l}\text { 3- Food rumors affect the name } \\
\text { and fame of the rumored } \\
\text { restaurant directly. }\end{array}$ & 400 & 3.89 & 1.39 & 15.3 & 16.3 & 9 & 36.1 & 23.3 \\
\hline $\begin{array}{l}\text { 4- I do neither hear nor care about } \\
\text { food rumors }\end{array}$ & 400 & 4.11 & 1.39 & 14.2 & 16 & 10.8 & 32.5 & 26.5 \\
\hline $\begin{array}{l}\text { 5- Food rumors don't affects } \\
\text { having my food at a restaurant } \\
\text { again only if there are } \\
\text { evidences assure their } \\
\text { credibility. }\end{array}$ & 400 & 3.94 & 1.38 & 13.5 & 15.8 & 11 & 32.7 & 27 \\
\hline $\begin{array}{l}\text { 6- I discuss other people about } \\
\text { rumors objectivity and that } \\
\text { helps me to take a decision } \\
\text { about having or not having } \\
\text { food at a restaurant. }\end{array}$ & 400 & 4.15 & 1.39 & 12.8 & 16 & 10.3 & 30.3 & 30.6 \\
\hline $\begin{array}{l}\text { 7- I don't care about food rumors } \\
\text { which relevant to the most }\end{array}$ & 400 & 3.96 & 1.39 & 15 & 16.8 & 9.5 & 34.5 & 24.2 \\
\hline
\end{tabular}




\begin{tabular}{|l|l|l|l|l|l|l|l|l|}
\hline trusted restaurant & & & & & & & & \\
\hline $\begin{array}{l}\text { 8- My judge on food rumors } \\
\text { sometimes affected by } \\
\begin{array}{l}\text { someone's opinion or my } \\
\text { feelings towards their } \\
\text { objectivity. }\end{array}\end{array}$ & 400 & 4.13 & 1.41 & 14.8 & 15.5 & 10 & 31.7 & 28 \\
\hline Grand mean & 400 & 4.03 & & & & & & \\
\hline
\end{tabular}

$1=$ strongly disagree, $2=$ Disagree, $3=$ Neutral, $4=$ Agree, $5=$ strongly agree

From the previous table (3) it is clear that most respondents confirmed that there is an impact of food rumors on the purchase decision at grand mean (4.03). It indicates that the response rate is between people who approved and those who strongly approved .It means that food rumors affect the decision of customers.

The results showed that $(59.5 \%)$ of the respondents assured that the food rumors affect fast food in general, and this shows that when the customer hears a food rumor about a restaurant, he avoids eating outside and that agreed with (Lee, 2014) who said "negative product rumors often persist over an extended period and negatively can and do impact consumer attitudes toward the product or purchasing behavior even when the rumors are implausible" .About (59.6\%) of the respondents adopted that food rumors lead people not to eat fast food for a limited period Consistent with the study Kimmel (2004), (59.6\%) granted that the food rumors affect the reputation and name of a restaurant directly and according to the study (Krishnan, 2001).

The study also signed off that rumors lead to low productivity as it affects customer purchasing decisions, defame restaurants and hinder sales. the study found find that (59\%) of the respondents agreed on that they do not listen to food rumors and do not care about it at all; this shows that there are some people who do not care about food rumors.

The study found that $(59.8 \%)$ of the respondents confirmed that food rumors do not affect having food at the same restaurant again without evidence approves its credibility according to (Choi, 2017), and (60.1\%) agreed that discussing people's opinion about rumors helps them make their decision $t$ about having food at a restaurant again or not. This shows that some customers form their opinion about rumors from close people and friends, these opinions affect their decision about going to a restaurant or not. (58.8\%) of the respondents said that they were not affected by the food rumors related to the restaurants I trust in. This indicates the customers confidence in the name and brand of a restaurant that does not make him influenced by any rumor about it and that agreed with Kimmel (2004) who said that Restaurants with a high brand are less likely to believe rumors about them compared with low brand restaurants.

Also $(59.8 \%)$ of the respondents agreed that their judgment will be influenced sometimes by personal opinion and feelings towards the rumors. This indicates the impact of customer judgment by emotions and feelings which increases their dependence on self-reflection and increases the chances of critical thinking in interacting with rumors.

- The impact of food rumors on the mental image of a restaurant

Table (4.9): Descriptive statistics of the impact of food rumors on the mental image of a restaurant

\begin{tabular}{|c|c|c|c|c|c|c|c|c|}
\hline $\begin{array}{c}\text { The impact of food rumors on the } \\
\text { mental image of a restaurant }\end{array}$ & $\mathrm{N}$ & Mean & $\mathrm{SD}$ & \multicolumn{5}{|c|}{ Percentage } \\
\cline { 5 - 9 } & & & 1 & 2 & 3 & 4 & 5 \\
\hline $\begin{array}{c}\text { 1- Food rumors affect my general } \\
\text { impression towards a restaurant }\end{array}$ & 400 & 3.98 & 1.4 & 13.5 & 15 & 11.3 & 30.2 & 30 \\
\hline
\end{tabular}




\begin{tabular}{|l|c|c|c|c|c|c|c|c|}
\hline $\begin{array}{l}\text { and forming a negative image } \\
\text { about it. }\end{array}$ & & & & & & & & \\
\hline $\begin{array}{c}\text { 2- Food rumors affect the name and } \\
\text { trademark of a restaurant. }\end{array}$ & 400 & 4.14 & 1.43 & 15 & 15 & 11.5 & 28.2 & 30.3 \\
\hline $\begin{array}{c}\text { 3- Food rumors affect the } \\
\text { reputation and position of a } \\
\text { restaurant. }\end{array}$ & 400 & 4.04 & 1.37 & 13.3 & 16 & 11.3 & 32.8 & 26.6 \\
\hline $\begin{array}{l}\text { 4- Food rumors lead to lose } \\
\text { confidence in promotional } \\
\text { campaign. }\end{array}$ & 400 & 4.19 & 1.4 & 13 & 16.3 & 10.3 & 30.3 & 30.1 \\
\hline Grand mean & 400 & 4.09 & & & & & & \\
\hline
\end{tabular}

$1=$ strongly disagree, $2=$ Disagree, $3=$ Neutral, $4=$ Agree, $5=$ strongly agree

From the previous table (4), it is clear that most of the respondents assured that there is an effect of the food rumors on the mental image of the restaurant as grand mean (4.09). It indicates that the response rate between people who agreed and those who strongly agreed. It means that food rumors have an effect on the restaurant's mental image and for further clarification, the study found that $(60 \%)$ of the respondents confirmed the impact of food rumors on their general impression and on forming a negative image of a restaurant and that agreed with the study (Jeong, 2010), the study also approves that the impression of the customer affects the brand of the restaurant leading to the formation of a negative mental image. (58.5\%) assured that food rumors affect the name and brand of the restaurant based on the study Kimmel (2004), and the study also found that (59.6\%) of the respondents confirmed that the rumors of food affects the reputation and position of the restaurant in the mind of the customer and that according to (Aditya, 2014). Addition, (60.3\%) of the respondents agreed that the food rumors were caused by a lack of confidence in the restaurant's advertising campaigns and that agreed to (Tarus and Rabach, 2013).

\section{Research findings:}

The study includes (2) hypotheses which are based on the linear relationship and will be tested using Simple Linear Regression.

It is obvious from table (1) that the value of the correlation coefficient between the independent variable (Solutions), and the dependent variable (Purchasing-Decision) is (0.776), and the value of the coefficient of determination (R2) is (0.752), and value of the adjusted coefficient of determination (Adjusted R2) is (0. 702), and the value of ( $F=7.873 E 3)$ of table (2) and a statistically significant (0.000) which is lower than the level of statistical significance $(\alpha=0.05)$. This indicates that the combined independent variable (Solutions) is able to explain (70\%) of the changes that happened in the dependent variable (Purchasing-Decision), and the remainder is attributed to other factors.

Table (5) shows Model Summary ${ }^{\mathrm{b} 1}$
\begin{tabular}{|c|c|c|c|c|}
\hline \multicolumn{5}{|c|}{ Model Summary } \\
\hline $\begin{array}{c}\text { Mode } \\
1\end{array}$ & R & R Square & Adjusted R Square & Std. Error of the Estimate \\
\hline 1 & $.776^{\mathrm{a}}$ & .752 & .702 & .16439 \\
\hline \multicolumn{6}{|c|}{ a. Predictors: (Constant), Solutions } & \\
\hline
\end{tabular}


Table (6) Illustrates findings of Analysis of Variance (ANOVA ${ }^{1}$ ) to verify the significance of analysis model of Simple Linear Regression.

\begin{tabular}{|c|c|c|c|c|c|}
\hline \multicolumn{6}{|c|}{ ANOVA $^{b}$} \\
\hline Model & Sum of Squares & df & Mean Square & $\mathrm{F}$ & Sig. \\
\hline Regression & 212.763 & 1 & 212.763 & 7.873E3 & $.000^{\mathrm{a}}$ \\
\hline Residual & 10.755 & 398 & .027 & & \\
\hline Total & 223.518 & 399 & & & \\
\hline $\begin{array}{l}\text { a. Predictor } \\
\text { b. Depender }\end{array}$ & $\begin{array}{l}\text { stant),Solutions } \\
\text { lable,Purchasing } \\
\text { ision }\end{array}$ & & & & \\
\hline
\end{tabular}

Table (7) Clarifies Model Summaryb1 of Simple Linear Regression \& the Regression Coefficients (Coefficientsa1).

Coefficients $^{\mathrm{a}}$

\begin{tabular}{|c|c|c|c|c|c|}
\hline \multirow{2}{*}{ Model } & \multicolumn{2}{|c|}{ Unstandardized Coefficients } & $\begin{array}{c}\text { Standardized } \\
\text { Coefficients }\end{array}$ & & \multirow{2}{*}{$\mathrm{t}$} \\
& $\mathrm{B}$ & Std. Error & Beta & \\
\cline { 2 - 5 } & .080 & .038 & & 2.067 & .039 \\
(Constant) & .979 & .011 & .976 & 88.731 & .000 \\
\hline
\end{tabular}

a.DependentVariable:Purchasingdecision

H1. There is impact of the solutions and procedures used by local restaurants to handle food rumors on the customer purchasing decision.

Regarding hypothesis (1), In table (7), it seems that there is a presence of a statistically significant standard and non-standard coefficient of linear regression equation on the independent variable (Solutions), as the value of $(\mathrm{t}=88.731)$ with a statistically significant $(0.000)$ which is lower than the level of statistical significance $(\alpha=0.05)$, which shows the rejection of the null hypothesis and accepting the alternative, which states: " H1. There is impact of the solutions and procedures used by local restaurants to handle food rumors on the customer purchasing decision. And so, there is significance for the standard coefficient of linear regression equation whose value amounted to (.976) and non-standard is (.979).

These results agreed to Choi ( 2017), Bordia and DiStaso ( 2015) and Kimmel (2010).

From the preceding results indicate that there is a significant impact of the methods and solutions used by local restaurants on the customer purchasing decision.

Table (8) shows Model Summary ${ }^{\mathrm{b} 1}$

\begin{tabular}{|c|c|c|c|c|}
\hline \multicolumn{5}{|c|}{ Model Summary } \\
\hline Model & $\mathrm{R}$ & R Square & Adjusted R Square & $\begin{array}{c}\text { Std. Error of the } \\
\text { Estimate }\end{array}$ \\
\hline 1 & $.771^{\mathrm{a}}$ & .743 & .740 & .19683 \\
\hline
\end{tabular}


International Journal of Heritage, Tourism and Hospitality Vol. (13), No. (2), September, 2019 By: Faculty of Tourism and Hotels, Fayoum University

\begin{tabular}{|c|c|c|c|c|}
\hline \multicolumn{5}{|c|}{ Model Summary } \\
\hline Model & $\mathrm{R}$ & $\mathrm{R}$ Square & Adjusted R Square & $\begin{array}{c}\text { Std. Error of the } \\
\text { Estimate }\end{array}$ \\
\hline 1 & $.771^{\mathrm{a}}$ & .743 & .740 & .19683 \\
\hline \multicolumn{4}{|r|}{ a. Predictors: (Constant), Solutions } \\
\hline
\end{tabular}

It is obvious from table (8) that the value of the correlation coefficient between the independent variable (Solutions), and the dependent variable (MENTAL IMAGE) is (0.771), and the value of the coefficient of determination (R2) is (0.743), and value of the adjusted coefficient of determination (Adjusted R2) is (0. 740), and the value of $(F=6.571 E 3)$ of table (5) and a statistically significant (0.000) which is lower than the level of statistical significance $(\alpha=0.05)$. This indicates that the combined independent variable (Solutions) is able to explain (74\%) of the changes that happened in the dependent variable (MENTAL IMAGE), and the remainder is attributed to other factors.

Table (9) Illustrates findings of Analysis of Variance (ANOVA ${ }^{1}$ ) to verify the significance of analysis model of Simple Linear Regression.

ANOVA $^{\mathrm{b}}$

\begin{tabular}{|c|c|c|c|c|c|}
\hline Model & Sum of Squares & $\mathrm{df}$ & Mean Square & F & Sig. \\
\hline 1 Regression & 254.578 & 1 & 254.578 & $6.571 \mathrm{E} 3$ & $.000^{\mathrm{a}}$ \\
\hline Residual & 15.419 & 398 & .039 & & \\
\hline Total & 269.996 & 399 & & & \\
\hline
\end{tabular}

a. Predictors: (Constant), Solutions

b. Dependent Variable: mental image

Table (10) Clarifies Model Summaryb1 of Simple Linear Regression \& the Regression Coefficients (Coefficientsa1).

Coefficients $^{\mathrm{a}}$

\begin{tabular}{|c|c|c|c|c|c|}
\hline \multirow[t]{2}{*}{ Model } & \multicolumn{2}{|c|}{$\begin{array}{c}\text { Unstq23wzcfandardized } \\
\text { Coefficients }\end{array}$} & $\begin{array}{l}\text { Standardized } \\
\text { Coefficients }\end{array}$ & \multirow[t]{2}{*}{$\mathrm{t}$} & \multirow[t]{2}{*}{ Sig. } \\
\hline & B & Std. Error & Beta & & \\
\hline 1 (Constant) & 244 & .046 & & 5.295 & .000 \\
\hline ppp & 1.071 & .013 & .971 & 81.064 & .000 \\
\hline
\end{tabular}

a. Dependent Variable: mental image

H2. There is impact of the solutions and procedures used by local restaurants to handle food rumors on mental image.

Regarding hypothesis (2), In table (10), it seems that there is a presence of a statistically significant standard and non-standard coefficient of linear regression equation on the independent 
variable (Solutions), as the value of $(\mathrm{t}=81.064)$ with a statistically significant $(0.000)$ which is lower than the level of statistical significance $(\alpha=0.05)$, which shows the rejection of the null hypothesis and accepting the alternative, which states: " H1. There is impact of the solutions and procedures used by local restaurants to handle food rumors on mental image. "; and so, there is a significance for the standard coefficient of linear regression equation whose value amounted to (.971), and non-standard is (1.071).

These results agreed to Kotler \& Keller(2006), Ogba \& Tan( 2009) and Tarus \&Rabach(2013). From the preceding results indicate that there is a significant impact of the methods and solutions used by local restaurants on the customer mental image.

\section{Recommendations and future research:}

Restaurant managers should do more work on differentiating their image, specifically through symbols and branding, restaurants should consistently provide quality products and services, such as serving food in promised time, serving ordered food accurately, and staff should be knowledgeable about menus, convenient operating hours, and ensure appearance the need for restaurant managers to follow the so-called (clinic rumors) and rely on these clinics on the need to be on the sites of public networks to deal with those rumors in a manner that suits them and verify the sources of rumors and promoters in order to address them by the necessary means . Restaurant managers should keep in mind that the management of image components is a longterm measure for achieving high revenue goals. Therefore, restaurant marketers must be equipped with a detailed knowledge of the important attributes of restaurant image, such as a frequented dining area, appropriate sound level, prompt service, differentiated image, cleanliness, cheerful and enchanting, long history, and familiarity. For future research it is recommended that same study can be conducted on other hospitality is like small hotels and it can also be applied to local restaurants in Egypte ,also recommended Future Research to identify the procedures followed by restaurant managers to resolve the crisis of food rumors.

\section{References}

Aditya, S. (2014). Role of Brand Familiarity in Combatting Rumors. Journal of Marketing Development and Competitiveness, 8(3), 120-129.

Coombs, W. T. (2007). Protecting organization reputations during a crisis: The development and application of situational crisis communication theory. Corporate Reputation Review, 10 (3), 163-176.

Coombs, W.T. (2012), Ongoing Crisis Communication, $3^{\text {rd }}$ ed., Sage, Thousand Oaks, CA, Vol. 16 , No.2

Choi, J. (2017). Brand Crisis Management in the Restaurant Industry (Doctoral dissertation, The Ohio State University).

Dalal, D. K., Diab, D. L., \& Tindale, R. S. (2015). I Heard That...: Do rumors affect hiring decisions? International Journal of Selection and Assessment, 23(3), 224-236.

Dwivedi, M., Shibu, T. P., \& Venkatesh, U. (2007). Social software practices on the Internet: Implications for the hotel industry. International journal of contemporary hospitality management, 19 (5), 415-426.

Frandsen, F., \& Johansen, W. (2011). The study of internal crisis communication: towards an integrative framework. Corporate Communications: An International Journal, 16(4), 347-361.

Jaques, Tony; (2008), A Case Study Aproach to Issue and Crisis Management, vol.12 (3), 192203. 
Jeong, EunHa. (2010). Customers' perception of green practices in restaurants, Purdue University.

Kaur, T. (2013). Role of social media in building image of an organization as a great place to work. ASBBS Proceedings, 20 (1), 546.

Keeffe, Michael J. and John R. Darling; (2008), Transformational Crisis Management in Organization Development: The Case of Talent Loss at Microsoft, vol. 26, No (4), 43-58.

Khatib, F. (2016). Impact of social media characteristics on prchase decision: Empirical study of Saudi customers in Asser. International Journal of Business and Social Science, vol 7 (4). 41-50.

Kimmel, A. J., \& Audrain-Pontevia, A.-F. (2010). Analysis of commercial rumors from the perspective of marketing managers: Rumor prevalence, effects, and control tactics. Journal of Marketing Communications, vol.16 (4), 239-253.

Kimmel, A.J. (2004). Rumors and rumor control: A manager's guide to understanding and combating rumors. Mahwah, NJ: Lawrence Erlbaum Associates.

Kotler, P. and Keller, K.L. (2006), Marketing Management, $12^{\text {th }}$ ed., Prentice Hall, Upper Saddle River, NJ. Little, K. (2016). One year after Chipotle's E. coli crisis, chain still struggling.

Krishnan, B. C., \& Hartline, M. D. (2001). Brand equity: is it more important in services? Journal of services marketing, 15(5), 328-342.

Lee, J. K. (2014). The effect of the Internet on homogeneity of the media agenda: A test of the fragmentation thesis. Journalism \& Mass Communication Quarterly, 84(4), 745-760.

McCreadie, R., Macdonald, C. and Ounis, I. (2015), "Crowdsourced rumour identification during emergencies", Proceedings of the International Conference on World Wide Web Companion, ACM, New York, NY, 965-970.

Ogba, Ike-Elechi and Zhenzhen, B. (2009). Exploring the impact of brand image on customer loyalty and commitment in China, Journal of Technology Management in China, vol. 2. 132144.

Ryu, K., Han, H., \& Kim, T.H (2008). The relationships among overall quick-casual restaurant image, perceived value, customer satisfaction, and behavioral intentions. International Journal of Hospitality Management, vol. 27, 459-469.

Saaksjarvi, Maria. (2017). How rumors and preannouncements foster curiosity toward products. European Journal of Innovation Management, Vol. 20 (3), 350-370.

Schulz, R. N. (2012). Effects of branding on restaurants 'image: a case of selected restaurants in nairobi, kenya. European Journal of Business and Social Sciences, 1(8), 56-66.

Tarus, Daniel and Rabach, Nicholas. (2013). Determinants of customer loyalty in Kenya: does corporate image play a moderating role? The TQM Journal, Vol. 25 (5), 473-491. 